\title{
An examination of student outcomes in studio chemistry
}

\author{
Alan L. Kiste, ${ }^{\star a}$ Gregory E. Scott, ${ }^{a}$ Jesse Bukenberger, ${ }^{b}$ Miles Markmann ${ }^{a}$ and \\ Jennifer Moore ${ }^{c}$
}

\begin{abstract}
Twenty years ago, a major curriculum revision at a large, comprehensive university in the Western United States led to the implementation of an integrated lecture/laboratory (studio) experience for our engineering students taking general chemistry. Based on these twenty years of experience, construction of four purpose-built studio classrooms to house the majority of the remaining general chemistry courses was completed in 2013. A detailed study of the effects of the entire ecology of the studio experience on student success was initiated at that time. Data from content knowledge pre- and post-tests, learning attitudes surveys, and student course evaluations show positive effects on student performance, the development of more expert-like learning attitudes, increased student engagement, and increased student-instructor interactions vs. the previous separate lecture and laboratory instruction for nonengineering students. Our data also show that an associated new peer Learning Assistant program increases student engagement while also having positive impacts on the Learning Assistants themselves.
\end{abstract}

\section{Introduction}

The laboratory has long been an integral component of chemistry education. While some have questioned whether chemistry laboratory instruction is effective given its time and cost (Hofstein and Lunetta, 1982, 2004), many of these criticisms revolve around a lack of well-aligned and communicated objectives (Reid and Shah, 2007). Quantitative and qualitative surveys of faculty have shown that the degree to which laboratory work complements other stated course learning goals is highly variable (Bruck et al., 2010; Bretz et al., 2013). Moreover, students express dislike when lecture and laboratory are not well-aligned (Bieron et al., 1996), and concurrent enrollment in laboratory has been shown to improve retention and performance in introductory chemistry lectures (Matz et al., 2012). Because of these concerns about time, cost, and laboratory alignment with course learning objectives, instructional strategies in introductory chemistry courses have evolved to include emphasizing laboratory as the central component (Bopegedera, 2011; Hopkins and Samide, 2013), integration of laboratory components into lecture (Larsen et al., 2013), and a complete integration of laboratory with all other components of the course in what we refer to as a studio course.

\footnotetext{
${ }^{a}$ Department of Chemistry and Biochemistry, California Polytechnic State University, 1 Grand Ave., San Luis Obispo, CA 93407, USA. E-mail: akiste@calpoly.edu

${ }^{b}$ Industrial and Manufacturing Engineering Department, California Polytechnic State University, 1 Grand Ave., San Luis Obispo, CA 93407, USA

${ }^{c}$ Mathematics Department, California Polytechnic State University, 1 Grand Ave., San Luis Obispo, CA 93407, USA
}

The studio model of an integrated lecture-laboratory experience was introduced to our chemistry program in 1994 (Bailey et al., 2000), though it was limited to the two-quarter introductory chemistry sequence for engineering majors until 2013. In 2013, we transitioned the majority of our remaining introductory chemistry courses into the integrated studio environment in new classrooms custom-built from the ground up for this specific purpose. At that time, we redesigned many of our laboratory experience activities to be more collaborative and added undergraduate Learning Assistants (LAs) based on the model developed at University of Colorado - Boulder (Otero et al., 2006). In our current model, the studio chemistry courses meet for either three 110 minute sessions or two 170 minute sessions each week in either 48- or 64-person studio classrooms. The courses are taught by a faculty member with assistance from either one or two undergraduate LAs depending on class size. In these studios, classes frequently transition between laboratory work, computer simulations, small-group discussions, problem solving, direct instruction, and formal and informal assessments. Thus, it is not just a binding of lecture and lab as the title integrated lecture-laboratory might imply.

Since our initial work on the studio model, other similar studio models for providing an integrated learning experience were developed. These include the studios introduced in physics at Rensselaer Polytechnic Institute (RPI) (Cummings, 1999), the Student-Centered Activities for Large Enrollment Undergraduate Programs (SCALE-UP) developed at North Carolina State University (Beichner et al., 2007; Gaffney et al., 2008), the TEAL project at MIT (Dori and Belcher, 2005), studio chemistry 
courses at the University of Michigan (Gottfried et al., 2007) (which have since been discontinued), and studio biology at Mount St. Mary's in Los Angeles (Nogaj, 2013). There are, however, several characteristics that distinguish the studio chemistry studied here from these other implementations. Of note, in the University of Michigan implementation, graduate students led the studio sessions, whereas faculty teach all of our studio sections with assistance from undergraduate LAs. Also, whereas RPI reduced its contact hours by one-third when transitioning from a traditional to studio model (Cummings, 1999; Wilson and Jennings, 2000), we have kept our contact hours (six hours per week) constant. Additionally, the teaching assistants in the RPI program received no additional training (Cummings, 1999), whereas our LAs receive two hours of training each week. This training consists of approximately one hour of specific training on the upcoming activities including: (1) how to set up, calibrate, and use spectrometers, gas chromatographs, and other equipment, (2) how to ask divergent, leading questions that lead students to discovering their own answers to questions, (3) how to assess student competence in using techniques like spectroscopy, titrations, graphing and data analysis, (4) how to manage and motivate students to be effective and efficient at using their time during the activities, and (5) how to manage safety and waste handling issues. The second hour of training is a discussion of primary chemistry education research literature designed to link research with their classroom practice. The research articles discussed in training include articles on understanding common student misconceptions (e.g. Ozmen, 2004), students' difficulties linking macroscopic phenomena with nanoscopic models through symbolic representations (e.g. Johnstone, 1982; Gabel et al., 1987; Gabel, 1993, 1998; Keig and Rubba, 1993; Kozma and Russell, 1997; Wu et al., 2001; Chittleborough, 2014), and evidence-based research on best practices in curriculum design, pedagogy, and assessment (e.g. Cole, 2015; Lamba, 2015; Taber, 2015).

Our LA model is loosely modeled after the LA program developed at the University of Colorado - Boulder (Otero et al., 2006) and implemented elsewhere (Goertzen et al., 2011). In addition to the LA model, there have been many other peer-guided learning models described in the research literature including PAL, PLTL and SSG (Topping and Ehly, 1998; Coppola et al., 2001; Varma-Nelson and Coppola, 2005). However, in most of these implementations as well as most examples of the LA model, the peer learning opportunities happen outside of the regular classroom. Our implementation is different in that LAs assist the faculty member in facilitating the primary classroom rather than leading a separate course meeting. At the same time, our LAs are not simply laboratory teaching assistants, working with students only during laboratory activities. In addition, we know of no reports describing the use of LAs in a studio classroom environment. In our implementation, the LA is responsible for assisting the instructor with encouraging and moderating small group discussions, providing assistance to individual students during problem-solving activities, discussions, and laboratory activities, monitoring safety, and serving as a positive role model to our students. Previous research has demonstrated that LAs may be effective at these tasks in ways that are qualitatively different from the instructor because students see peer instructors as more relaxed, engaging, and relatable than faculty (Denise Kendall and Schussler, 2012). In addition to the benefits to the students in the classroom, given the results of previous research on the LA model, we anticipate that the LA program should also provide benefits to the LAs themselves: (1) the LAs strengthen their understanding of fundamental chemistry concepts by teaching those concepts, (2) the LAs would graduate with considerable teaching experience, which would be particularly useful for students who receive teaching assistantships in graduate school, and (3) the LAs may use their experiences to inform their career choices (Otero et al., 2006, 2010; U.C. Boulder LA Program, 2012).

Here we present a multi-focal study of the studio classroom, measuring student exam performance relative to a traditional lecture ( $3 \mathrm{~h}$ per week) and lab $(3 \mathrm{~h}$ per week, concurrent enrollment with lecture), student learning attitudes, student and faculty opinions of the learning environment, and an analysis of the effects of the integrated Learning Assistant program. While there are several analyses of studio classrooms in the literature which primarily focus only on student grades as an outcome variable (Cummings, 1999; Wilson and Jennings, 2000; Dori and Belcher, 2005; Gottfried et al., 2007; Taylor, 2008; Cotner et al., 2013; Nogaj, 2013), this study provides a more complete, novel, multi-component analysis of the entire ecology of the unique studio classroom implementation by examining not only the studio versus traditional environments, but also the effect of the inclusion of LAs, and the variability across sections providing a more holistic picture by using multiple evaluation instruments. Additionally, it would be difficult to disaggregate the effects of the studio curriculum and pedagogy, and the inclusion of Learning Assistants in the classroom. Finally, because the LAs are also students in our program, we aim to understand what impact participation in the studio has on the general chemistry knowledge and teaching attitudes of the LAs.

\section{Theoretical framework}

Though the studio chemistry curriculum has continued to grow and mature from its initial introduction in 1994, we continue to use the latest evidence-based approaches to inform the development of our pedagogy and curriculum (Cole, 2015). In particular, these pedagogical and curricular reform efforts are guided by social constructivist learning theories that emphasize the importance of active learning that is socially mediated and which offers opportunities to explore multiple levels of representation: macroscopic, symbolic, and nanoscopic (Johnstone, 1993).

Active learning. Meta-analyses of hundreds of research reports from STEM fields in general (Freeman et al., 2014) and chemistry in particular (Towns and Kraft, 2011) demonstrate that active learning experiences increase student content knowledge, positively influence students' learning attitudes, and decrease failure rates. Active learning pedagogies such as Problem-Based Learning (Hmelo-Silver, 2004), inquiry-based 
laboratory and computer simulation activities (Stieff and Wilensky, 2003; Bransford et al., 2004; Lamba, 2015), interactive demonstrations (Posner et al., 1982; Zimrot and Ashkenazi, 2007), and peer-instruction (Coleman, 1998; Crouch and Mazur, 2001; Varma-Nelson and Coppola, 2005) deemphasize passive accumulation of knowledge and instead emphasize active construction of new knowledge. With this in mind, the studio curriculum is expressly designed to include multiple hands-on integrated active learning activities each class period. We believe this design allows a level of integration of hands-on activities that greatly exceeds what could be accomplished from simultaneous enrollment in separate lecture/laboratory courses. The activities are not just taught concurrently, but are comprehensively integrated using the principles of backwards design to align the learning goals of each activity with pedagogy and assessment (Wiggins and McTighe, 2005).

In addition to a curriculum designed to foster student activity, the physical classroom space has itself been transformed from one designed only for lecture to one that encourages hands-on explorations of chemical phenomena, simulations, and modeling. In the studio, students are seated in clusters of six or eight (see Fig. 1), with a significant amount of space between the clusters to allow the students and the instructional staff to circulate freely. Students have ready access to computers as well as laboratory glassware, instrumentation, and chemicals located at their clusters or stationed in buffets around the room.

Socially mediated. Students in the studio classroom are not just actively constructing knowledge on their own, but that knowledge construction occurs in the context of a curriculum and physical space intentionally designed to foster continual student interaction (Vygotsky, 1978). There is much evidence that learning opportunities that foster collaboration can assist students in the construction of new understandings (Johnson et al., 1998, 2007; Johnson and Johnson, 1999). Our activities are designed to be cooperative (Coppola and Lawton, 1995), and many, in fact, cannot be completed by one student without cooperating closely with several peers, sometimes including crowd-sourcing data with the entire class using cloud-based services (Denton, 2012). Again, the physical space the close proximity of students to each other and their physical orientation facing each other - reinforces the cooperative nature of each class experience. Though there is an instructor station, it is visually deemphasized and students' attention is directed at each other, rather than at the front of the room.

Visualization. Chemistry students have particular difficulty linking the macroscopic phenomena observed in chemistry laboratory activities with the nanoscopic particulate nature of matter as well as the symbolic representations that chemists use to describe both, which has been shown to pose a significant difficulty in learning chemistry for students (Johnstone, 1982; Gabel et al., 1987; Gabel, 1993, 1998; Keig and Rubba, 1993; Kozma and Russell, 1997; Wu et al., 2001; Chittleborough, 2014). In the studio classroom, the use of molecular modeling and simulation software including Models 360 and WebMO (Prat-Resina et al., 2016; The Concord Consortium, 2008) before, during, and after observing macroscopic phenomena is integrated directly into the hands-on activities. We believe this tight integration forces students to explain, on a nanoscopic level, the results from the macroscopic phenomena they observed in the laboratory using chemical symbolism. At the same time, the inclusion of the technology in the classroom means that these explorations of visualizations can happen immediately while the laboratory activity is happening, rather than some time after the experience (Taber, 2015).

\section{Case study}

Rather than the traditional model of lecture followed by a single laboratory experience up to a week later, in the studio short direct instruction episodes and small group discussions can contextualize the material while students are actively working on gathering, analyzing, and reporting data with their peers. This alone, however, does not distinguish the studio from a well-designed laboratory meeting where students interact with each other and the instructor. The potential advantages of the studio approach are best seen when looking across multiple class meetings where activities can be broken into pieces and interspersed with relevant instruction over time. In practice, this means that students can collect data on one day while learning a technique, have time to process the data, then return another day to perform a related experiment with a higher level of sophistication. An example of a series of activities that incorporate socially mediated, active learning opportunities that emphasize visualization is our module on intermolecular forces adapted in part from Csizmar et al. (2011). While the

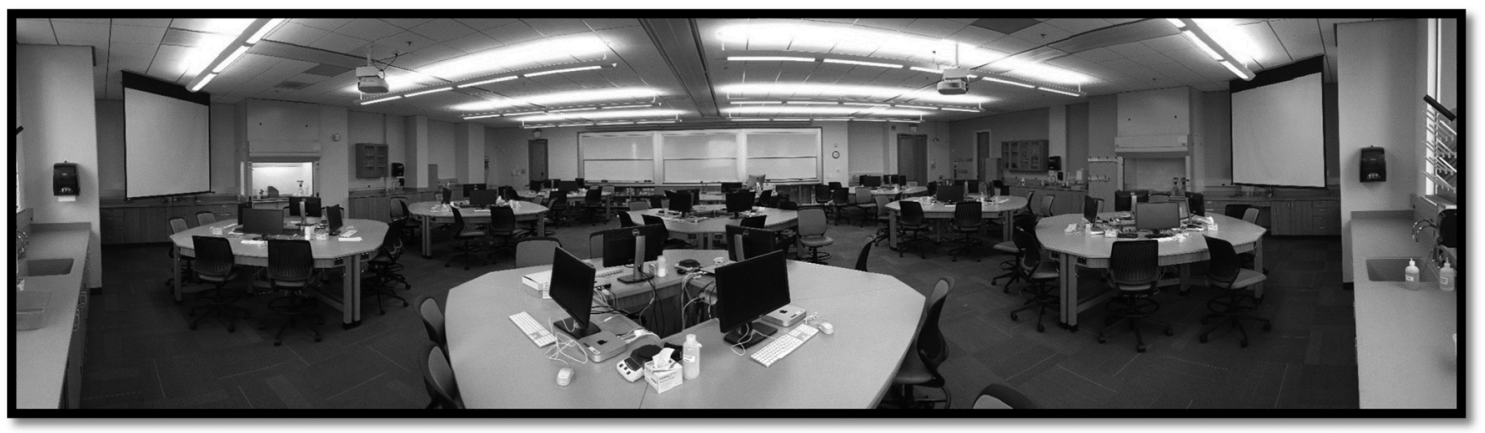

Fig. 1 Panoramic photograph of a 64-student studio classroom. 
data collection described below could all be done in a single 3 hour lab period, the students have an opportunity to draw conclusions from each part before being exposed to increasing levels of complexity in the activity. These activities described below follow a previous week of activities introducing students to drawing Lewis structures, using the structures they draw to infer common bonding structures, translating between Lewis structures and physical and computation molecular models, and using those models to identify isomers (Kiste et al., 2016).

Day 1. Students get a brief interactive lecture on electronegativity and bond polarity. This includes time for solving practice problems while the instructor and learning assistants circulate to help students. The students then work collaboratively at the studio computers to complete an activity using WebMO (Mashl et al., 2013) to compute partial charges, electrostatic potential maps, and molecular dipole moments for a variety of molecules. Students relate the bond dipoles to the overall molecular dipole and discover the role that symmetry plays in permanent dipole moments. The instructor leads a whole class-discussion to summarize the activity and previews that polarity will be one factor that influences how molecules interact with each other.

Day 2. Before class, students complete an out-of-class exercise drawing molecular structures for a series of isomers and looking up the physical properties of the compounds they draw such as boiling point. In addition, students watch a brief 5 minute video introducing them to the set-up of the GCs they will use and proper injection and data analysis techniques. Then, in class, the students have small group discussions about the structures of molecules and making predictions about shape and polarity based on their previous class activity. The students then perform gas chromatography using Vernier Mini GCs, injecting each of the molecules from their exercise as well as a mixture of the molecules. Students are led to two conclusions from this: (1) the retention times are the same regardless of whether the molecules were introduced in a pure form or in a mixture, and (2) there is a correlation between retention times, boiling points, and molecular structures. The instructor then provides some direct instruction about the types of intermolecular forces and the students work in small groups to make predictions about a series of molecules with increasing structural complexity.

Day 3. Before class, students complete an out-of-class exercise where they answer questions about the relationship between boiling point and molecular structure by watching simulations (The Concord Consortium, 2008) and referring to their data from the previous class meeting. After an in-class review of the previous two activities and an opportunity to practice solving problems for simple molecules, students engage in another activity with data collection and molecular modeling. Each group of eight students receives four mixtures containing three compounds each. Each pair of students generates a gas chromatogram for their mixture and performs a computational modeling exercise to examine the structural characteristics of the molecules in the mixture, thus using visualization to link the nanoscopic and macroscopic levels of description. These mixtures are constructed so that each pair of students will be able to draw conclusions about a single particular structural characteristic such as molecular mass, or the presence or absence of hydrogen bond donors and acceptors and the effect of that characteristic on the intermolecular interactions and thus macroscopic properties (e.g. boiling point) of the molecule. The students then work in their small groups to share their data and conclusions with each other to develop a more sophisticated model. Since no single student or group has all the data, the trends cannot be elucidated without working cooperatively with other students and their data. While doing so, the instructor and learning assistants engage students in small group discussions about the nuances of how the structure relates to the strength of intermolecular forces. Because students are already versed in the GC technique and because they have already carried out earlier modeling exercises relating electrostatic potential maps and dipole moments, they are prepared to tackle more complicated questions. They are able to think critically about ideas such as why some non-polar molecules may have higher boiling points than some molecules that can hydrogen bond.

Through this multiple-class sequence, the cognitive load of learning either an experimental or computational technique is separated from applying the technique to more complicated systems. Pre-class activities are designed to prime students for learning and provide instruction about techniques. In-class instruction of new ideas is also broken into smaller pieces, interleaved into the appropriate places within the scaffolded activity. Like the majority of our activities, this activity is designed to be modular with multiple out-of-class preparation activities (Carnduff and Reid, 2003), and a multi-part procedure so that it is flexible and can be integrated into other classroom activities such as small group discussions, problem-solving practice, direct instruction, and formative assessments to create a coherent, integrated, and holistic experience.

\section{Research questions}

Given our theoretical framework that socially mediated active learning opportunities that emphasize visualization should increase student content knowledge, positively influence students' learning attitudes, and decrease failure rates by assisting students in making connections between macroscopic phenomena and nanoscopic levels of description, compared to traditional separated lecture and laboratory classes:

(1) What is the effect of the studio environment on student content knowledge, as measured by student performance on the final exam?

(2) What is the effect of the studio environment on course grades and failure rate?

(3) What is the effect of the studio environment on the development of student learning attitudes?

(4) How do students and faculty evaluate the studio environment compared to traditional separated lecture/laboratory classes? 
(5) What effect does the LA experience have on LAs' general chemistry content knowledge?

\section{Methods}

Our theoretical framework not only guided the research questions we have asked, but also the methodologies we used to answer those questions. In order to examine the collaborative, active learning environment of the studio classroom we examined student content knowledge, but also included affective measures such as student learning attitudes and student and instructor opinions about their experiences. These additional measures allowed us to examine aspects of the environment that are not readily described by student final exam grades alone, such as the level of student-instructor and student-student interaction vs. a traditional setting, as well as students' conceptual connection-making, and their atomic/ molecular-level chemistry perspectives.

\section{Study context}

720 students in the first-quarter course in a year-long introductory chemistry sequence from the fall of 2012 (Traditional) and fall of 2013 (Studio) volunteered to participate in the study across 9 sections at a large, comprehensive university in the Western United States. Of the 720 students, 36 were removed from the study due to the omission or incorrect entry of the student ID number on the diagnostic or final exam. This represents 653 unique individuals, as 31 students were repeating the course in the second term studied. 426 students were included from fall of 2012 and 258 from fall of 2013. The demographics of the 684 students included in the study are summarized in Table 1 . These courses are taken primarily by first- or second-year students, but there are students of junior and senior standing in the analysis as well. Many of the students listed as sophomores were first-year students, but their standing is calculated on units earned including AP and transfer credit. More students came from the College of Science and Mathematics than from any other college, but many students also came from both the College of Agriculture Food and Environmental Sciences and the College of Engineering. Very few students came from the University's other colleges. No data on gender or ethnicity was collected for this study due to institutional restrictions regarding the collection of that information.

All 22 LAs from the fall of 2013 and winter of 2014 quarters voluntarily participated in data collection at the beginning and end of the first quarter during which they were LAs, that is, while there was some overlap between students who were LAs in the fall and those who were LAs in the winter, each LA participated in data collection only once, in the first quarter that they were an LA. All LAs were chemistry or biochemistry majors and ranged from sophomore to senior standing. A second group of 8 students, who were not LAs, volunteered to participate in the study. This group of students was also all chemistry or biochemistry majors, had completed similar
Table 1 Demographics of students included in final exam analysis from Fall 2012-Fall 2013 for 684 subjects

\begin{tabular}{lll}
\hline & $\begin{array}{l}\text { Fall 2012 } \\
\text { Traditional } \\
(n=426)\end{array}$ & $\begin{array}{l}\text { Fall 2013 } \\
\text { Studio } \\
(n=258)\end{array}$ \\
Class standing & $1.8 \%$ & $18.9 \%$ \\
\hline Freshman & $30.4 \%$ & $50.9 \%$ \\
Sophomore & $45.0 \%$ & $23.3 \%$ \\
Junior & $22.8 \%$ & $6.9 \%$ \\
Senior & & \\
& & \\
College & $42.3 \%$ & $43.3 \%$ \\
Science \& mathematics & $25.9 \%$ & $34.9 \%$ \\
Agriculture, Food \& Environmental Sciences & $19.6 \%$ \\
Engineering & $27.9 \%$ & $0.7 \%$ \\
Liberal Arts & $2.7 \%$ & $0.4 \%$ \\
Business & $0.9 \%$ & $1.1 \%$ \\
Architecture \& Environmental Design & $0.2 \%$ & \\
& & \\
Average GPA & & 2.93 \\
University GPA & 2.98 & 3.91 \\
High School GPA & 3.95 & \\
& & \\
Average SAT & & 640 \\
SAT Math & & \\
SAT Reading & 655 & 1262 \\
Combined SAT & 633 & \\
Average ACT & 1288 & 27.7 \\
ACT Math & & 27.1 \\
ACT Reading & & \\
Composite ACT & 28.3 & \\
\hline
\end{tabular}

coursework relative to the LA group, and met the same GPA requirements to be LAs, but had not applied to the program. Neither the LA group nor the peer group had taken any studio courses prior to participation in the study and the peer group did not participate in the studio courses in any way during the study.

\section{Student performance}

To assess the differences between studio and traditional courses, several instruments were used. Prior preparation for the course was measured using the 2006 form of the American Chemical Society California Chemistry Diagnostic Exam, a validated, nationally normed exam used as a placement exam for introductory college general chemistry courses (KR-21 = 0.83) (Russell, 1994; Legg et al., 2001). Post-course content knowledge was evaluated using performance on a common final exam, which was not returned to students, and strict exam security was maintained in order to use it over the multiple years of the study. This exam has an average student score of $65.5 \%$, an overall point biserial of 0.38 , the point biserials for individual questions range from 0.18 to 0.58 , and KR-20 $=0.87$. These statistics remain consistent year over year. From 2012 to 2013 there were some curricular changes in the course notably the removal of a section on calorimetry - and questions pertaining to that topic were removed from the final exam. To make the most objective comparison between the two terms, only the 39 questions (out of 45 on the exams) common to both Fall 2012 and Fall 2013 exams were used in this study. 
We compared average student performance on the final exam from four traditional sections of the first quarter of introductory chemistry offered in the fall of 2012 to five studio sections of the same course in the fall of 2013 taught by the same four instructors (one instructor taught two studio sections in 2013). Because all sections of this course were converted to the studio in the same quarter and there was no simultaneous random assignment of students into experimental and control groups, the effect of studio courses is confounded with time.

To verify that any changes observed were not better explained by a change in the incoming student population, the diagnostic assessment was given at the beginning of the term. The assessment exhibited a slight non-linear relationship with the final exam grade, where students who did well on the diagnostic also did well on the final exam, but students who scored much higher or lower on the diagnostic test only performed slightly better or worse than the students who scored slightly above or below average respectively. Because of the nonlinear relationship, students were sorted into clusters based on their diagnostic score instead of directly using the raw diagnostic score in the analysis. A hierarchical clustering technique was used to sort students into 4 clusters; the number of clusters was chosen based on a visual inspection of the clustering hierarchy (see Appendix 1) and the same technique was used for sorting students in both the traditional and studio treatment groups. This allowed us to use the ordinal clustered data in place of the continuous diagnostic score to account for the non-linear relationship. While there are other statistical methods that can be used on non-linear data, we utilized hierarchical clustering in order to examine whether or not any predictors demonstrated differential effects based on student preparation as measured by the diagnostic exam. To measure the effects of a studio-style course, several additional factors were included in the model. In addition to whether or not the student was enrolled in a studio course, we included in our model which instructor the student enrolled under, which section the student enrolled in, whether or not the student enrolled in a supplemental workshop (an optional, two-hour, once per week, peer-led problem-solving recitation section which could be taken by students enrolled in either the traditional or studio environment), and the student's level of preparedness, as measured by the diagnostic exam.

When each level of a factor can co-occur with each level of every other factor, the experiment is considered a crossed design; if levels of one factor can only co-occur with one level of another factor, the first factor is said to be nested under the second factor. In nested designs, each level of the nested factor becomes an experimental unit for the factor under which it is nested (Montgomery, 2013). Because each section can only be offered by one instructor and must be taught as either a studio or traditional course, the Section factor is nested under the Instructor and Studio factors. Thus, when comparing the studio courses to traditional courses, we are analyzing the variability between sections rather than the variability between individual students. This reduces the power of our test, but the results are still significant. Both the Instructor and Section factors are random factors because the instructors and sections measured here are only a random sample of the possible instructors and sections that could be tested. The effects of these particular instructors and sections are only of interest to control the variance that is introduced by these factors in general. No other student demographics are used as covariates in this model to avoid multicollinearity with the diagnostic test. In total there are 2 levels of the Studio and Supplemental Workshop factors, 4 factors of the Instructor and Diagnostic Cluster factors, and 9 levels of the Section factor.

\section{Learning attitudes}

Students' learning attitudes were measured with the Colorado Learning Attitudes about Science Survey for Use in Chemistry (CLASS-Chem) (Adams et al., 2006, 2008a). This validated survey probes student beliefs about learning chemistry and compares those beliefs to expert responses. Students took the CLASS-Chem survey on the first day of class (pre) and the end of each quarter just before the final exam (post) in the Fall 2013 studio courses. Survey data were analyzed using the published CLASS Analysis guidelines (Physics Education Technology and Physics Education Research Group at Colorado, 1998). Instructor 1 did not provide post-quarter surveys, so the analysis was limited to the students from Instructors 2,3 , and 4 . Of the 167 students from these sections, 126 completed both pre- and post-surveys that could be matched by correct student ID numbers. One of these surveys was not included because the student failed to complete 5 of the survey questions. The students who completed the CLASS survey closely mimic the performance of the overall population on the diagnostic exam; the distribution of students into the four diagnostic clusters is very similar for the overall population and the CLASS survey group.

\section{Opinion survey}

At the completion of the fall 2013 quarter, students and instructors were asked to complete a survey to provide their qualitative opinions about how the studio compares to a traditional course setting, rating each question on a Likert scale ( $\alpha=0.74$, for the student survey). The survey was informed by our theoretical framework as well as concerns that had been expressed by faculty and other researchers about the studio. For example, we asked questions about student-faculty, and student-student interaction, and connecting concepts in order to examine whether students believed that they were engaging more in socially mediated, active learning pedagogies in the studio classroom. Other questions, such as whether or not students had trouble staying focused, or were more nervous or uncomfortable in the studio were created to address concerns by faculty that the studio environment may be too busy for students to stay focused on their learning.

In addition, students completed a 13-question survey asking their opinions about how this course that included LAs compares to a course without LAs using a 1-5 Likert scale $(\alpha=0.72)$. We used questions designed to parallel those used for the 
studio portion of the survey. The complete survey can be found in Appendix 3. A total of 227 students completed the student survey ( $88 \%$ response rate) and 15 instructors who have taught in the studio completed the instructor survey (11 instructors in addition to the four whose students are included in this analysis). Several instructors also provided written reflections on their experiences teaching in the studio classrooms.

\section{Learning assistants}

To examine the impact of working in the unique studio environment, the LAs and their non-LA peer group also completed the 2006 American Chemical Society California Chemistry Diagnostic exam at the beginning of the quarter and completed the same common final that all introductory level general chemistry students are given at the end of the quarter. They were also given a questionnaire that consisted of 14 questions about the practice of teaching, general chemistry course material, and their interest in teaching as a career from materials produced by the University of Colorado - Boulder (Learning Assistant Program, 2012). Using Grounded Theory Analysis (Glaser, 1992; Glaser and Holton, 2007), their responses were coded with regard to their critical features and then collected into categories based on grouping the concepts, such as their comfort with the course material, the nature of their beliefs about pedagogy, and whether or not they expressed interest in teaching as a future career. Examples of words or phrases indicating subjects' high or low level of comfort with the course material and beliefs regarding pedagogy are shown in Table 2 . Inter-rater reliability on $50 \%$ of student responses showed a substantial $87.7 \%$ agreement (Cohen's $\kappa=0.75$ ).

Table 2 Examples of words and phrases used to code LA questionnaires Level of comfort with the course material

\begin{tabular}{ll}
\hline Comfortable & \\
Approachable & Fair \\
Navigate & Network \\
High standards & Mastering material \\
Fun & Positive experience \\
& \\
Uncomfortable & \\
Uncertain & Unfair \\
Unenthusiastic & Graduate prep \\
Unapproachable & Negative LA \\
Not challenging & Negative experience \\
\hline
\end{tabular}

Beliefs regarding pedagogy

Expert-like
Simulation
Collaboration
Multiple perspectives
Translator
Facilitate
Navigate
High standards
Novice-like
Uninformed
Suggest
Correcting

Assist
Exploration
Network
Efficient
Checkpoint
Concept reaffirming

Passive

Question answer

\section{Results}

\section{Student performance}

Table 3 shows the average final exam grades for studio classes for the first quarter of introductory chemistry in the fall of 2013 were higher than those of traditional classes in the fall of 2012. This trend was true for all sections taught by all four instructors in the study group. When controlling for student preparedness with the diagnostic exam, the average score on the final exam improved from the traditional to studio implementations within each of the four clusters. While we cannot explicitly rule out class-size effects, it should be noted that while the lecture size was larger in the traditional format, the lab sizes were comparable in both the traditional and studio implementations. The increase is larger for the lower three performing clusters, however this is likely a ceiling effect and not a differential effect of the studio based on student preparedness prior to enrollment.

The data also revealed a slightly higher average final exam grade for students who elected to enroll in a supplemental workshop. While enrollment in the optional workshop is subject to a self-selection bias, the benefit of enrolling in a supplemental workshop was greater for students in the studio classes than in the traditional setting. Students in all four diagnostic clusters benefited from enrolling in the supplemental workshop, though the majority (75\%) of students who elected to participate were in the lower two clusters.

The model indicates that the three factors: studio vs. traditional setting, diagnostic exam cluster, and supplemental workshop enrollment each have a significant effect $(p<0.02$ for each factor) on the final exam score. See Appendix 1 for additional information on the fixed effect test. In the context of the complete model, the two factors of interest, studio enrollment and Supplemental workshop enrollment, are both significant. Here we use the Least Squares mean (LS mean) as a more accurate estimate for the factor's effect than the mean

Table 3 Tabulation of sample size and mean final exam grade with standard error of the mean

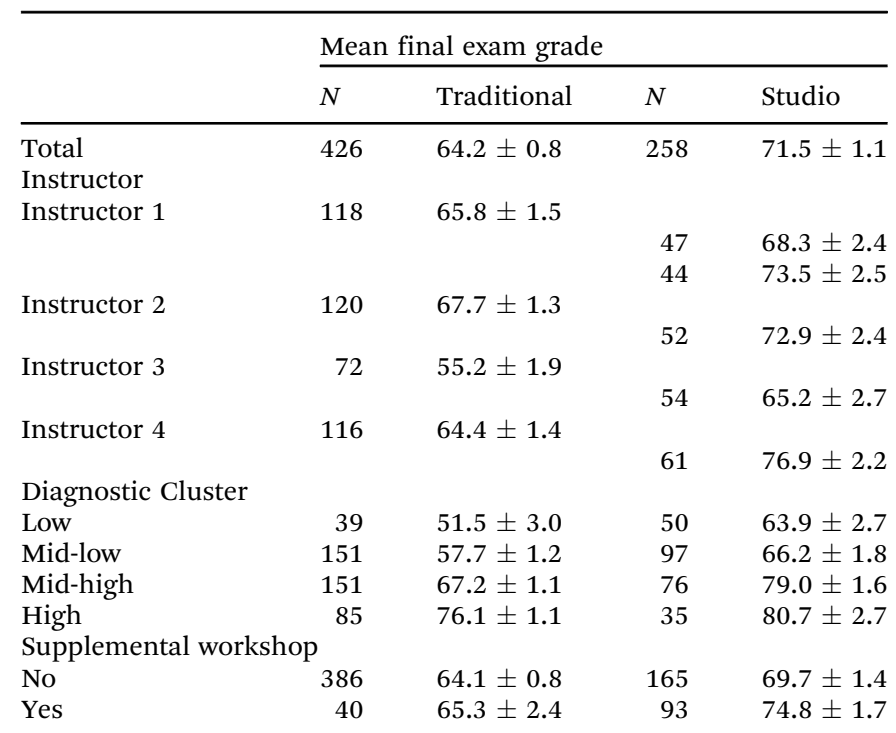


from the raw data because the LS mean controls for the other factors in the model. Consequently, the results here are the isolated effects of the studio and supplemental workshop treatments. Students enrolled in studio courses are expected to score $9.2 \%$ better on the final exam on average; the $95 \%$ confidence interval for the difference is $(3.5 \%, 15.0 \%)$. Similarly, the mean exam score from students who elect to enroll in supplemental workshops is expected to be $3.9 \%$ higher and the 95\% confidence interval for the difference is $(0.6 \%, 7.1 \%)$. See Appendix 1 for additional details.

We also examined the number of students who received repeatable grades $(\mathrm{D}, \mathrm{F}$, or $\mathrm{W})$ in the courses converted to the studio format (see Appendix 2). In the terms following the conversion to the studio format, there were decreases in the number of students who earned repeatable grades. There is large variability in repeatable grades between terms and while we cannot state that these decreases are statistically significant, the trend is in a favorable direction. The improvement in scores on the common final exam that can be attributed to the studio setting along with a decrease in repeatable grades suggests that the studio implementation has had a positive impact on grades and retention.

\section{Learning attitudes}

Students in the Fall 2013 introductory studio chemistry course completed the CLASS-Chem instrument on the first day of class and immediately prior to the final exam. Table 4 shows the shifts in favorable (expert-like) attitudes for students in the studio classes in this term. Students in these sections demonstrated shifts toward more expert-like learning attitudes, which is striking because for both CLASS-Phys and CLASS-Chem, downward shifts across most or all categories are typical in introductory courses (Adams et al., 2004, 2006, 2008a; Perkins et al., 2007).

While CLASS data was not collected for the traditional course in the fall of 2012 before all of the sections were converted to the studio format, a direct comparison to other CLASS data from the literature is informative. The last two columns of Table 4 compare the students in these studio classes to the 697 students of Adams et al., (2008a, 2008b). For every category, the students from the comparison study showed negative shifts over one semester of general chemistry I. Students in the studio courses, in contrast, only showed a negative shift in the category (Real World Connection) that was the most negative shift from the previous study. Positive shifts exceeding two standard errors were seen in all but two of the other categories for the studio courses, including increases in the "Personal Interest" and "Problem Solving: General" categories of $9 \%$ and $8 \%$, where the literature showed decreases of $9 \%$ and $6 \%$, respectively. Adams et al. suggested that shifts in students' beliefs on the CLASS instrument can be correlated to various teaching methods; the studio environment studied here appears to be quite promising as measured via this instrument. The Conceptual and Atomic-molecular Perspective categories showed particularly strong positive shifts, areas specifically targeted in the theoretical framework for the studio implementation.

Table 5 shows the CLASS survey data disaggregated by diagnostic cluster. The students who performed higher on the diagnostic exam tended to enter the course with more expertlike learning attitudes. In some cases, the students from the higher diagnostic clusters showed more favorable shifts in learning attitudes (e.g. Problem Solving: Confidence, Conceptual Learning) than students in lower clusters. In the case of the "Atomic-Molecular Perspective of Chemistry" category, the high cluster showed a much smaller shift than all three of the other clusters, though it was also the category where the pre-course scores for that cluster were most elevated relative to the other clusters. In most cases, however, the shifts between clusters were not distinguishable given the variances within the populations. This suggests that on the learning attitudes measured by the CLASS survey, the studio environment does not have a discernible differential effect on students clustered by their incoming level of preparation.

\section{Opinion survey}

While student opinions about pedagogy may not be particularly well-informed, we believe a measure of student satisfaction is valuable alongside more robust measures of learning outcomes and attitudes. Student responses regarding their opinions of studio courses relative to their experiences in traditional lecture/lab were overwhelmingly positive. While the majority of our students had not experienced a traditional lecture/ laboratory college-level chemistry course, given the science, agriculture, and engineering majors represented by population, many were simultaneously enrolled in lecture/laboratory

Table 4 CLASS survey scores for Fall 2013. The uncertainties listed for the shifts are the standard errors in the shifts

\begin{tabular}{|c|c|c|c|c|}
\hline Survey response categories & $\begin{array}{l}\text { Favorable precourse } \\
\text { response }(\%)\end{array}$ & $\begin{array}{l}\text { Favorable postcourse } \\
\text { response }(\%)\end{array}$ & $\begin{array}{l}\text { Post-pre response } \\
\text { shift }(\%)\end{array}$ & $\begin{array}{l}\text { Post-pre response shift from } \\
\text { Adams et al. }(2008 \mathrm{a}, 2008 \mathrm{~b})(\%)\end{array}$ \\
\hline Overall & 60 & 66 & $6 \pm 1$ & $-5 \pm 1$ \\
\hline Personal Interest & 54 & 63 & $9 \pm 2$ & $-9 \pm 2$ \\
\hline Real World Connection & 69 & 64 & $-5 \pm 3$ & $-12 \pm 2$ \\
\hline Problem Solving: General & 70 & 78 & $8 \pm 2$ & $-6 \pm 2$ \\
\hline Problem Solving: Confidence & 77 & 81 & $4 \pm 3$ & $-8 \pm 2$ \\
\hline Problem Solving: Sophistication & 50 & 62 & $12 \pm 3$ & $-4 \pm 2$ \\
\hline Sense Making/ Effort & 75 & 75 & $0 \pm 2$ & $-10 \pm 1$ \\
\hline Conceptual Connections & 60 & 71 & $11 \pm 2$ & $-4 \pm 2$ \\
\hline Conceptual Learning & 45 & 57 & $12 \pm 2$ & $-2 \pm 2$ \\
\hline Atomic-Molecular Perspective of Chemistry & 60 & 72 & $12 \pm 3$ & $-2 \pm 2$ \\
\hline
\end{tabular}


Table 5 CLASS survey scores for Fall 2013 broken down by diagnostic cluster. The Pre and Post columns indicate the percent of students with a favorable (expert-like) learning attitude at the beginning and end of the term, respectively. The uncertainties listed are one standard error of the mean

\begin{tabular}{|c|c|c|c|c|c|c|c|c|c|c|c|c|}
\hline Survey response categories & \multicolumn{3}{|c|}{ Low cluster $(n=22)$} & \multicolumn{3}{|c|}{ Mid-low cluster $(n=43)$} & \multicolumn{3}{|c|}{ Mid-high cluster $(n=39)$} & \multicolumn{3}{|c|}{ High cluster $(n=21)$} \\
\hline ver & & $57 \pm 3$ & 2 & $57 \pm 2$ & & $7 \pm 2$ & $63 \pm 2$ & & $8 \pm 2$ & $69 \pm 3$ & 7 & $7 \pm 3$ \\
\hline Real World Cc & $66 \pm 6$ & $47 \pm 7$ & $-19 \pm 8$ & $68 \pm 4$ & $63 \pm 4$ & $-5 \pm 4$ & $68 \pm 5$ & $71 \pm 5$ & $2 \pm 5$ & $75 \pm 6$ & $69 \pm 6$ & $-6 \pm 6$ \\
\hline Prob & $59 \pm 4$ & $65 \pm 5$ & $6 \pm 6$ & $64 \pm 3$ & $74 \pm 4$ & $10 \pm 3$ & $77 \pm 3$ & $83 \pm 3$ & $6 \pm 3$ & $81 \pm 5$ & $89 \pm 3$ & $8 \pm 5$ \\
\hline & & $68=$ & $-3 \pm 7$ & 74 & $80 \pm 4$ & $5 \pm 4$ & & & 4 & & $=3$ & $11 \pm 6$ \\
\hline & 5 & $44 \pm 5$ & $10 \pm 6$ & 45 & $58 \pm 4$ & $12 \pm 4$ & 60 & 70 & $10 \pm 4$ & & $73 \pm 4$ & $15 \pm 7$ \\
\hline Con & $35 \pm 5$ & $40 \pm 6$ & $5 \pm 6$ & $46 \pm 4$ & $52 \pm 4$ & $6 \pm 4$ & $49 \pm 4$ & $65 \pm 4$ & $16 \pm 4$ & $47 \pm 6$ & $69 \pm 5$ & $22 \pm 6$ \\
\hline Atomic-Molecular Perspective of Chemistry & $52 \pm 6$ & $62 \pm 6$ & $11 \pm 7$ & $57 \pm 4$ & $72 \pm 4$ & $15 \pm 4$ & $59 \pm 5$ & $74 \pm 4$ & $15 \pm 4$ & $77 \pm 6$ & $80 \pm 5$ & $3 \pm 6$ \\
\hline
\end{tabular}

courses in biology, physics, and/or engineering and/or had enrolled in lecture/laboratory courses previously. Those who had not had such experiences could indicate a "neutral" answer on the Likert-style survey. Responses were simplified to agree, disagree, and neutral with a rating of 1 or 2 being agree, 3 being neutral and 4 or 5 being disagree. The results, shown in Fig. 2, indicate that the students clearly prefer studio style chemistry courses over traditional courses. The majority of students agreed with each statement that compared studio courses positively to traditional courses and the majority of students disagreed with negatively worded statements. Instructor responses, shown in Fig. 3 were also generally positive or neutral.

Both student and instructor responses indicated a preference for the studio courses and felt that it led to better peer-peer and peer-instructor interactions, conceptual connections, and was overall better for learning chemistry. These responses run parallel to the CLASS-Chem attitudes survey results that showed growth toward expert-like thinking in areas such as conceptual connections. Considering that the studio's design and the curriculum we have developed are based on disciplinebased education research in chemistry (Cole, 2015), these results are not surprising. Particularly promising, however, are these positive opinions given that previous studies have demonstrated that students are sometimes resistant to the implementation of non-traditional teaching practices that add a higher level of interaction or minimize lecture (Knight and Wood, 2005; Silverthorn, 2006; Cummings, 2008; National Research Council, 2015).

One concern that was expressed by faculty prior to the broad implementation of the studio model was that the physical

\section{Student Opinions of Studio Courses}

More academically rigorous.

Better suited overall for learning chemistry.

I solve more problems.

I interact more with my peers.

I interact more with my instructor.

I enjoy the course more.

I ask more questions.

I am more motivated.

I am more likely to attend class.

Concepts are better connected.

More time spent on direct instruction.

I have more trouble staying focused.

I feel nervous or uncomfortable.
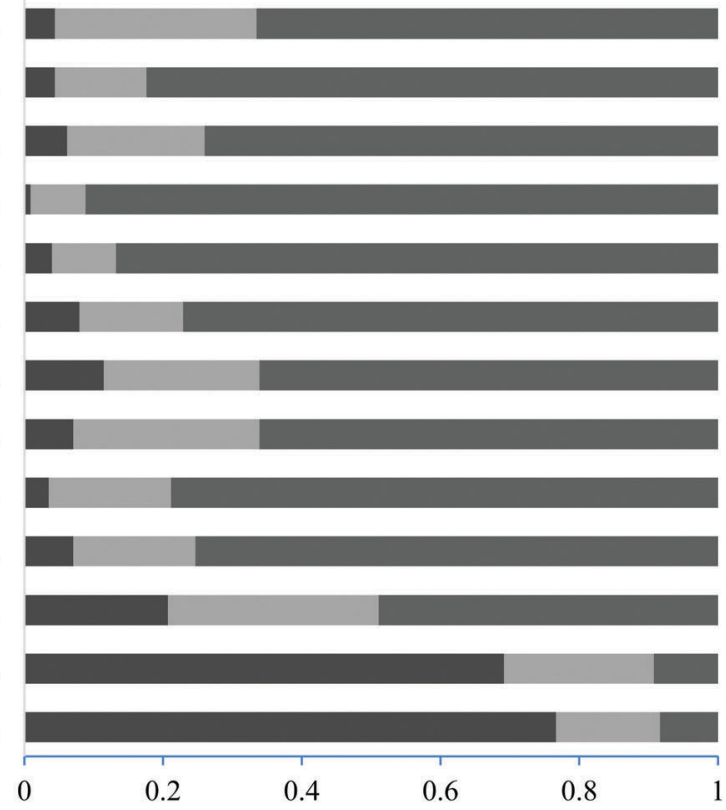

- Disagree Neutral Agree

Frequency

Fig. 2 Positive, neutral, and negative student responses to course evaluation questions. Each question began with the stem: "Compared to a traditional lecture/lab course, in the studio classroom ..." $(n=227)$. 


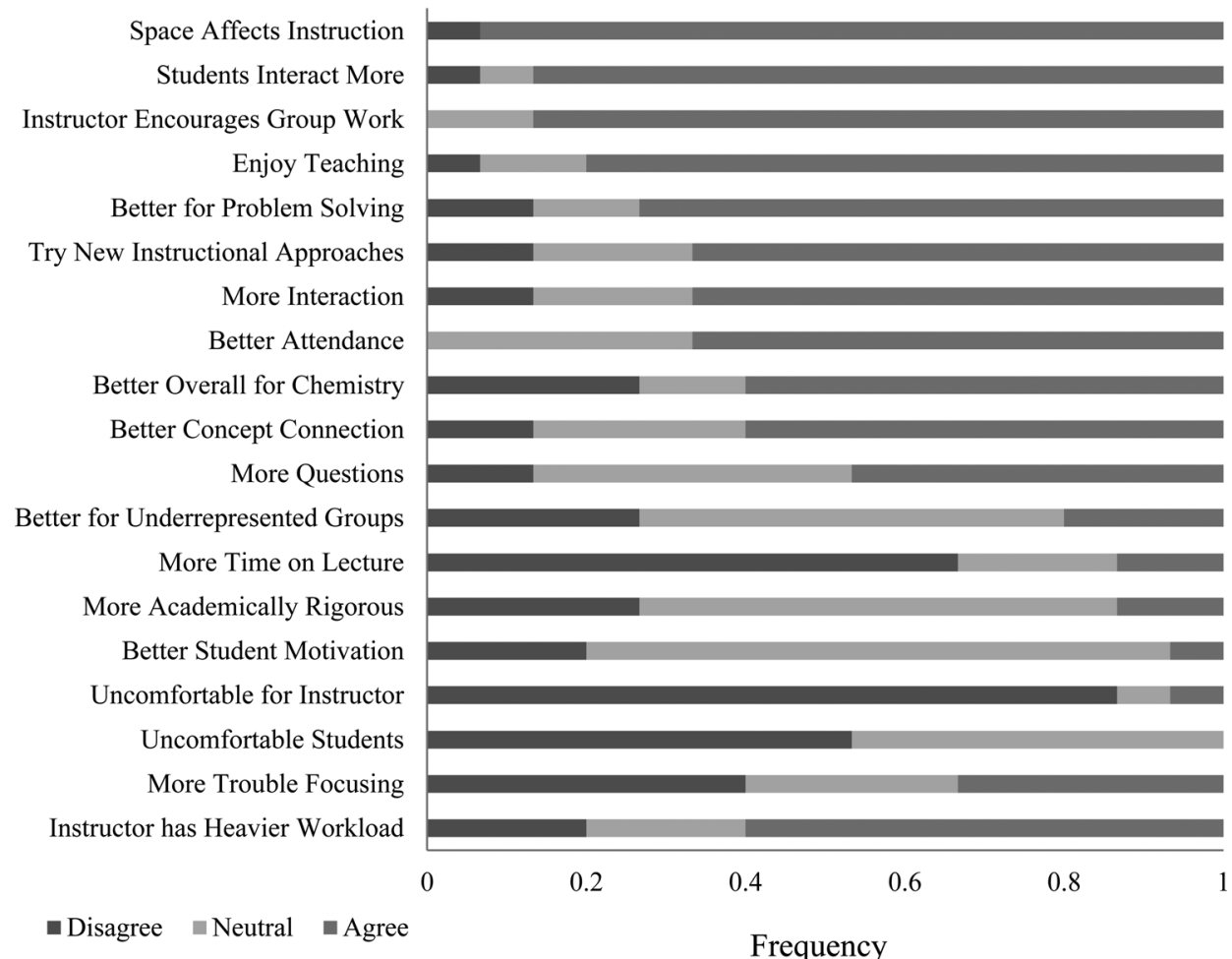

Fig. 3 Positive, neutral, and negative instructor responses to course evaluation questions. Each question began with the stem: "Compared to a traditional lecture/lab course, in the studio classroom ..." ( $n=15)$.

space - the computers, the close arrangement of students facing each other, etc. - would be distracting to students. However, students report that they do not have a greater trouble focusing in class $v s$. a traditional classroom setting and the majority of faculty do not believe the setting is distracting.

Faculty report that the workload for teaching studio is higher than for a traditional course. However, given that these surveys were conducted at the beginning of the changeover to the studio environment, the high workload may be due to the work required to adapt to the environment initially. In spite of the faculty's perception that the workload was higher, the majority reported that they enjoyed teaching in the studio more than teaching in a traditional setting.

Several instructors provided written comments regarding their experiences teaching in the studio classrooms:

Instructor 1: "The opportunity to move fluidly between instructional modes allows for a more student-centered classroom, rich with opportunities for formative assessment. The ability to break laboratory experiments into multiple components allows students to do more guided inquiry with an opportunity to process information and develop connections that are more difficult in the constraints of a traditional lecture/lab format."

Instructor 2: "Compared to a traditional lecture/laboratory course, the studio affords far more flexibility to closely integrate all course activities at any time, including laboratory activities, demonstrations, simulations, computational modeling, and direct instruction. However, in a traditional lecture/laboratory course, students have a single lab at some point during the week. Thus, depending on the timing of lecture and lab, it is possible for students to have a laboratory experiment a week before or after they encounter the concepts in lecture, which makes the class experience less cohesive for students."

Instructor 3: "The dynamic, interactive nature of the classroom constantly challenges me to find new ways of presenting material and better ways of getting students involved in the learning in a hands-on manner. Being able to teach in an environment in which I can present content to the entire class and then immediately have the students apply this content in a hands-on laboratory activity is so amazing - it's the way science should be taught and how students can best learn I think."

Instructor 4: "In the studio classroom we have integrated the lecture and lab curricula and literally torn down the wall between the lecture and lab. I have been able to use lab experiences to motivate discussion and introduce material or reverse this and supplement discussion with hands-on lab activities. I can stop and start with one-on-one instruction, peer discussion in groups, even traditional, and more passive, lecturing while I sandwich these activities around lab experiences. All of this leads to a much more dynamic, active, and yes sometimes even chaotic environment where peer learning and learn-by-doing strategies can be easily employed. Of course all of this activity requires more preparation on the part of the instructor but the rewards more than compensate." 


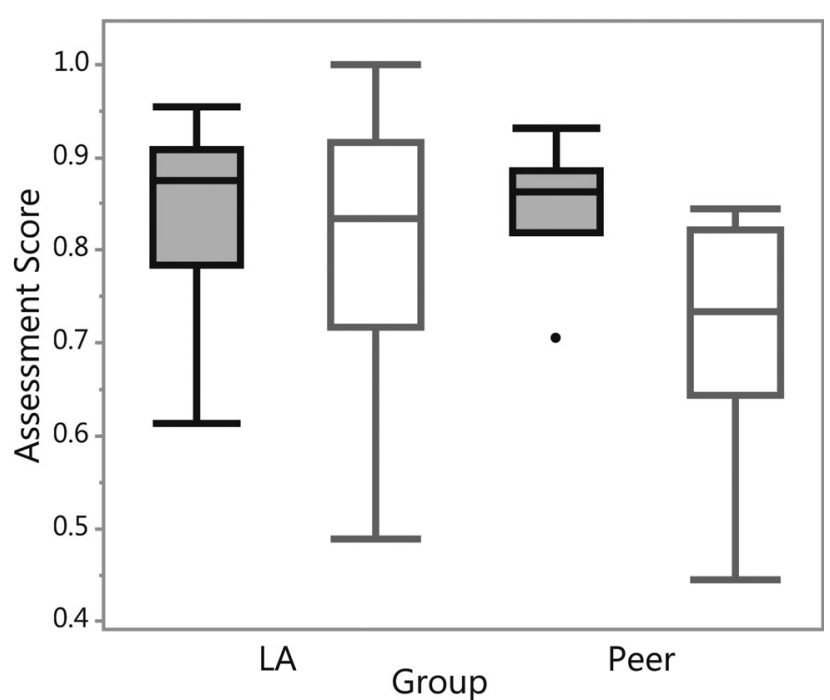

Fig. 4 Comparison of diagnostic (gray box) and final exam performance (white box) for LAs $(N=22)$ and the non-LA peer group $(N=8)$.

\section{Learning assistants}

Sixteen Learning Assistants (LAs) and seven of their non-LA peers volunteered to take the same diagnostic and final exam that students in the first-quarter general chemistry class did. Fig. 4 shows that the two groups showed similar performance on the diagnostic exam at the beginning of the quarter with the range for the LAs including lower scores than the range for the peer group. On the final exam at the end of the quarter, the group of LAs out-performed their peers. While we cannot state with confidence that the means for the two groups are different on the final exam due to the small sample size ( $p=0.07$ in a one-way ANOVA), it is striking to note that nearly $50 \%$ of the LAs scored higher on the final exam than all of their non-LA peers. Additionally, nearly $75 \%$ of the LAs scored above the median peer score on the final exam. Given that the LA group had slightly lower scores on the diagnostic exam, this suggests that the LA experience may significantly improve general chemistry knowledge.

Table 6 shows the results of coding the questionnaires for both the LAs and their non-LA peers. The total number of statements about their beliefs regarding good teaching are higher than their novice beliefs for both groups, and these do not change significantly during the quarter, nor are they

Table 6 The total number of statements made by both groups regarding their beliefs about pedagogy and their comfort with general chemistry content. (Percentages of all statements coded are given in parentheses.)

\begin{tabular}{|c|c|c|c|c|c|}
\hline & & \multicolumn{2}{|l|}{ LAs } & \multicolumn{2}{|c|}{ Non-LA peers } \\
\hline & & Pre (\%) & Post (\%) & Pre (\%) & Post (\%) \\
\hline \multirow[t]{2}{*}{ Pedagogy } & Novice & 135 (39) & $116(37)$ & $41(36)$ & 49 (39) \\
\hline & Expert & $211(61)$ & $195(63)$ & $73(64)$ & $78(61)$ \\
\hline \multirow[t]{2}{*}{ Content } & Comfortable & $116(74)$ & $122(75)$ & $50(83)$ & $41(82)$ \\
\hline & Uncomfortable & $41(26)$ & $42(25)$ & $10(17)$ & $9(18)$ \\
\hline
\end{tabular}

Table 7 The total number of statements made by both groups regarding the likelihood of engaging in teaching careers in the future. (Percentages of all statements coded are given in parentheses.)

\begin{tabular}{llllll}
\hline & LAs & & & \multicolumn{2}{c}{ Non-LA peers } \\
\cline { 2 - 3 } \cline { 5 - 6 } & Pre $(\%)$ & Post $(\%)$ & & Pre $(\%)$ & Post $(\%)$ \\
\hline Yes & $24(33)$ & $27(41)$ & & $11(41)$ & $4(21)$ \\
No & $28(39)$ & $22(33)$ & & $10(37)$ & $8(33)$ \\
Maybe & $20(28)$ & $17(26)$ & $6(22)$ & $11(46)$ \\
\hline
\end{tabular}

significantly different between groups. Comparing both groups' statements regarding their comfort with the general chemistry content, both groups reported being equally confident before and after the quarter, despite the fact that the final exam data indicated content knowledge substantially increased for the LAs, but not for their peers.

Table 7 shows the number of statements that LAs and their peers made that were positive, negative, or undecided regarding a future teaching career at the K-12 or university levels. There was no significant difference in either group over the quarter, nor between groups. However, there was a larger percentage of statements by students in the non-LA peer group that were less certain, positively or negatively, about teaching as a career. While this could be a selection effect, initially the percentage of positive statements made by the non-LA peer group about a future teaching career is higher (41\%) than the percentage of positive statements made by LAs $(33 \%)$. The uncertainty of the Non-LA peer answers suggests that the experience of being an LA increases LAs' certainty about their interest or disinterest in a future teaching career.

As with their opinions about the studio course, student opinions of the inclusion of LAs in the course were overwhelmingly positive, as indicated by the opinion survey they completed. Responses were simplified to agree, disagree, and neutral with a rating of 1 or 2 being agree, 3 being neutral and 4 or 5 being disagree. The results, shown in Fig. 5 , indicate that the students clearly prefer courses that include LAs. The majority of students agreed with each statement that presented LAs in a positive manner and the majority of students disagreed with statements that portrayed LAs negatively.

\section{Discussion and conclusions}

Our goal with this research was to document as many aspects of our studio classrooms as possible in order to explore the entire ecology of the classroom and the ways in which different aspects of the intervention impact students. Unlike previous studies of studio classrooms which focused on only student performance as measured by final grades (e.g. Matz et al., 2012), we have utilized a multifocal analysis that examines the effect of studio $v s$. traditional environments, the effect of variability by section, and the impact of additional learning resources by measuring not only student performance, but learning attitudes and student and faculty beliefs. This holistic approach leads to several conclusions that can be made about the studio 
chemistry at this university as it stands today, nearly 20 years after it was first introduced.

Our model demonstrates that student content knowledge as measured by student performance on the final exam is a statistically significant $9 \%$ higher in the studio $v$ s. traditional classroom comparison. Other factors which play a role in the ecology of these classes are students' prior preparation as measured by the ACS diagnostic exam, and their enrollment in a supplemental workshop. We believe our data demonstrates that the studio environment is superior to the traditional environment for improving student content knowledge by engaging multiple modes of learning in a social environment with a highly cohesive curriculum in which students are continually tasked with linking the macroscopic and nanoscopic levels of chemistry through the use of chemistry symbols and representations (National Research Council, 1996; Schwartz et al., 1999; Bransford et al., 2004; Cole, 2015; Lamba, 2015). While the variability is too high to make conclusive statements about a decrease in DFW rate, there is a general downward trend in the data, which we will continue to explore.

Contrary to examples in the literature of general chemistry courses with separate lecture/laboratory components (Perkins et al., 2007; Adams et al., 2008b), students in our studio courses demonstrate significant shifts toward more expert-like learning attitudes. We posit that the integrated, highly hands-on, inquiry-based environment simulates the sorts of habits of thinking that experts rely upon and thus, students are more likely to become more expert-like in their attitudes toward learning chemistry than they would by sitting passively in a lecture. In addition, the highly collaborative, inquiry-based assignments, augmented by the close proximity afforded by the physical space itself likely contributes to students' development of more expert-like learning attitudes (Cooper, 1994; Cooper and Kerns, 2006; Cooper et al., 2008; Sandi-Urena et al., 2011; Sandi-Urena et al., 2012). While students who begin the course in a higher diagnostic cluster also begin the course with more expert-like learning attitudes, the overall shift in learning attitudes is similar for the top three clusters, though there are smaller positive and some negative shifts for the lowest cluster. The CLASS data was also informative in showing that additional efforts should be made to make stronger and more explicit real world connections in the content.

Both students and faculty are overwhelmingly positive about the studio environment and believe that students interact more with each other and with their instructor, that students are better able to connect concepts, that it increases student attendance, that it is a comfortable environment for students, and that it is better overall for learning chemistry. It is interesting that both students and faculty believe that studio increases attendance as compared to the traditional setting. We speculate that students realize that the highly cooperative, hands-on nature of the daily activities makes it difficult for them to miss class and still keep up with the material.

Written feedback from instructors indicates that they believe there are several aspects to the success of the studio environment: a curriculum that is more tightly connected than can be achieved through simultaneous enrollment in separate lecture and laboratory courses, a focus on active learning pedagogies, and greater flexibility. We are currently extending our research to explore how these and other factors contribute to student experiences and success.

\section{End of Quarter Student Evaluation Responses Regarding Comparing Classes With and Without Learning Assistants}

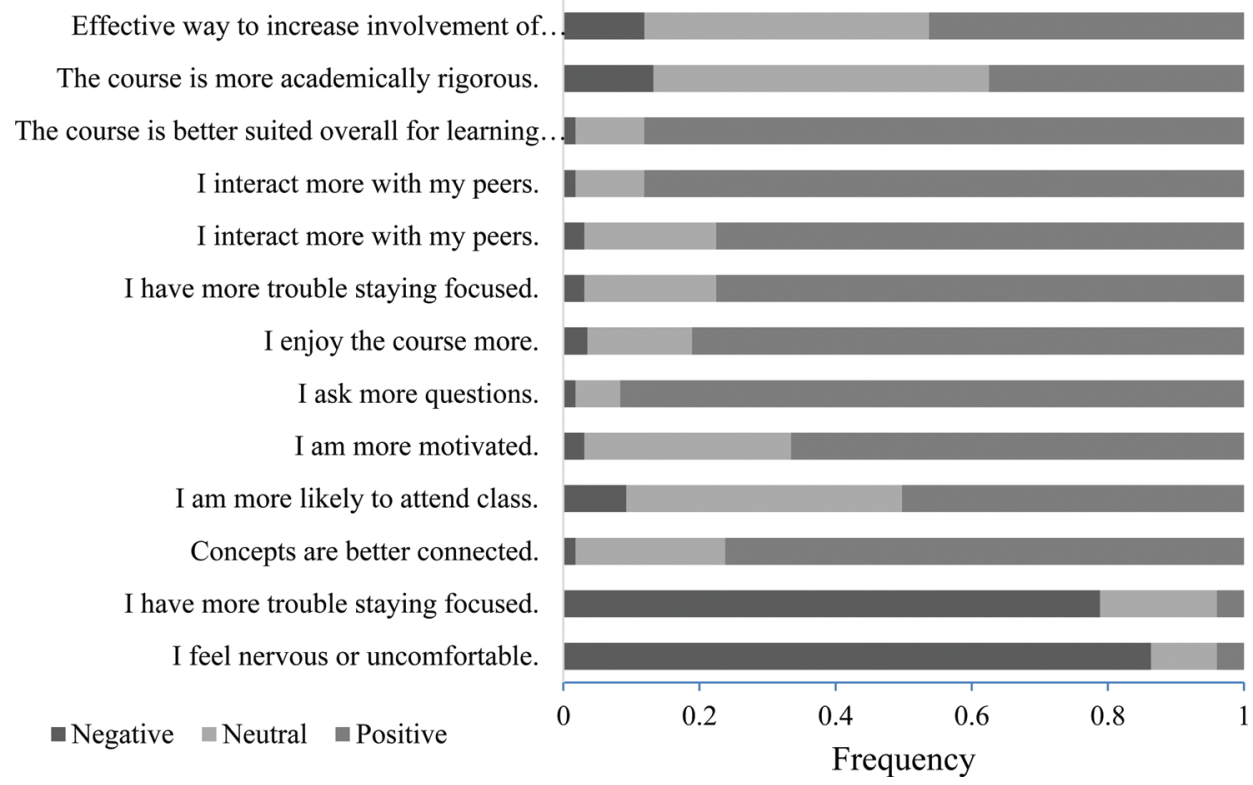

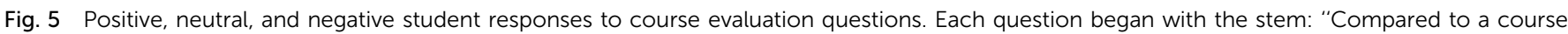
without Learning Assistants, in this class with Learning Assistants, ..." ( $n=227)$. 
Our LAs are an integral part of the studio experience and, as has been found in other implementations of LA programs around the country in non-studio environments (Goertzen et al., 2011), participation in our LA program in the studio instructional context greatly increased their content knowledge $v s$. their non-LA peers. This is not surprising given that they spent an additional 60 hours during the quarter in the classroom working with their students on hands-on chemistry activities along with the 20 hours of training per quarter. Participation in our LA program may also increase LAs' certainty about their future career plans in teaching.

Our theoretical framework specifies the important variables in the design of studio that influence our students' success are socially mediated, active learning opportunities that emphasize visualization in order to assist students in making connections between macroscopic phenomena and nanoscopic levels of description. As our results indicate, these experiences increase student content knowledge and decrease failure rates, compared to traditional separated lecture and laboratory classes. In addition, this study of our studio classrooms is one of only a small number examples in the literature showing students' learning attitudes becoming more expert-like over the duration of a course. Finally, both students and instructors emphasized the importance of active learning and cooperative interactions to be positive factors in their studio experience.

\section{Implications}

The results of this work demonstrate the utility of a curriculum of highly integrated, tightly cohesive laboratory work, computer simulations, small-group discussions, problem solving, direct instruction, and formal and informal assessments. Furthermore, to the extent that this level of integration can be achieved in other settings, we would expect to see similar increases in student performance, learning attitudes, and retention. Given the potential difficulty of implementing a full-scale studio program at some colleges and universities, we believe our research adds additional support for those pedagogical and curricular interventions which increase student interaction, hands-on learning opportunities, concurrent enrollment in lecture and laboratories, and enhance the cohesiveness of learning activities, but which can be carried out in more typical lecture and/or laboratory environments (Kober, 2015).

The implementation of a studio program is likely to be highly idiosyncratic due to the many varied goals of and demands on introductory general chemistry programs at other institutions. Large universities that utilize one faculty member to teach hundreds of students per hour in lecture halls would see a decrease in efficiency by adopting a studio model. Even if graduate students at these universities were trained to teach in an integrated environment, the facilities costs for creating studio spaces to accommodate their huge student populations might be prohibitive (Cotner et al., 2013). Some large universities that have developed studio programs have subsequently ended them (Coppola, B., personal communication, March 2016).
However, at smaller universities, implementing a studiostyle general chemistry program may be as efficient as or even more efficient than a separate lecture/laboratory program. In departments which do not utilize graduate student TAs, three 3 hour stand-alone general chemistry laboratories with 20-22 students would serve approximately as many students as our 64-student studio rooms, but would require three faculty members, rather than just one. In fact, within a few years, the savings in faculty time could pay for the cost of remodeling an appropriately sized lecture room - currently approximately \$250 000 (Gragson, D., personal communication, March 2016). In addition, the current new construction cost of building a stand-alone general chemistry laboratory to serve a smaller number of students would be approximately the same as (\$1500 per square foot) building a studio space that serves a larger number of students per hour with fewer faculty, is more pedagogically versatile, and is more efficient in terms of faculty time.

\section{Appendix 1. Student outcomes}

Fig. 6.

Tables 8 and 9.

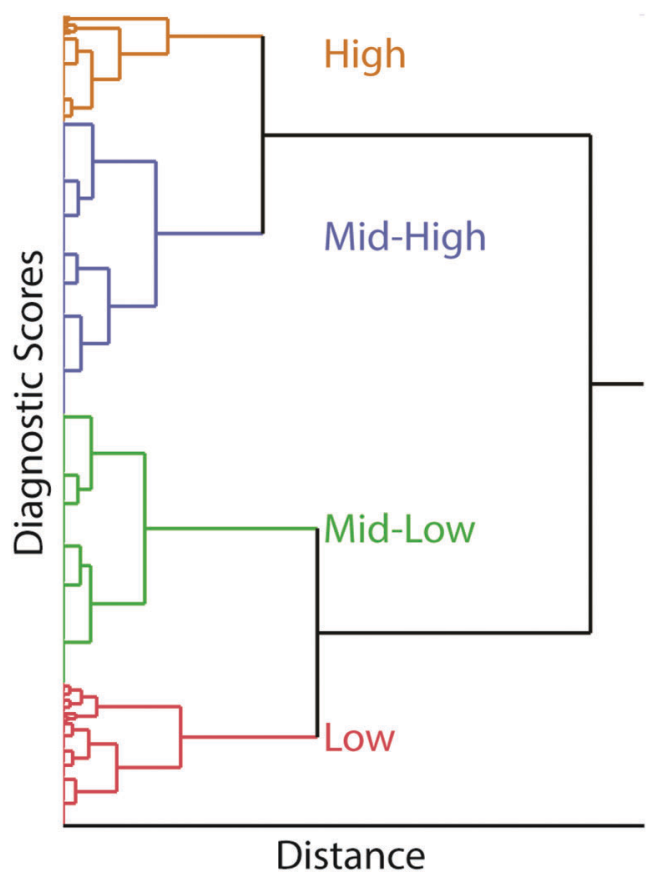

Fig. 6 Hierarchical clustering dendrogram of diagnostic scores, which shows four distinct clusters.

Table 8 Fixed effect test. The significance level was set at 0.05 for all tests and the model has an $R^{2}$ of 0.34

\begin{tabular}{lllll}
\hline Source & DF & DFDen & $F$ Ratio & Prob $>F$ \\
\hline Studio & 1 & 4.257 & 18.9084 & $0.0106^{*}$ \\
Supplemental workshop & 1 & 417.4 & 5.3426 & $0.0213^{*}$ \\
Diagnostic clusters & 3 & 674 & 77.9191 & $<0.0001^{*}$
\end{tabular}




\begin{tabular}{|c|c|c|c|c|c|}
\hline Factor & Level & Least squares mean & Standard error & Lower 95\% & Upper 95\% \\
\hline \multirow[t]{2}{*}{ Studio } & Traditional & 63.9 & 3.2 & 54.9 & 72.8 \\
\hline & Studio & 73.1 & 3.2 & 64.0 & 82.1 \\
\hline \multirow[t]{2}{*}{ Supplemental workshop } & No & 66.5 & 3.0 & 57.1 & 76.0 \\
\hline & Yes & 70.4 & 3.2 & 61.5 & 79.3 \\
\hline
\end{tabular}

\section{Appendix 2. Repeatable grades}

Fig. 7.

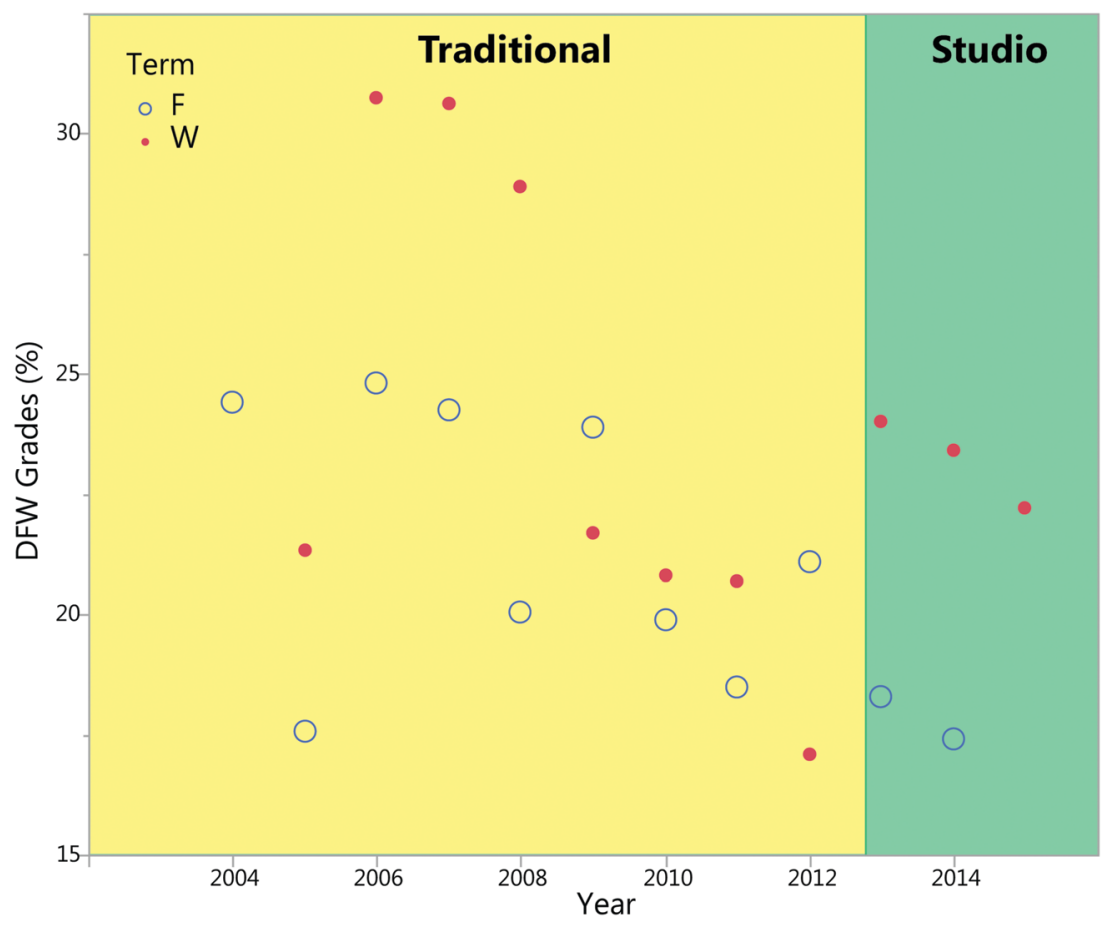

Fig. 7 Repeatable (D, F, and W) grades for the first-quarter course in a year-long introductory chemistry sequence for science majors before and after studio implementation.

\section{Appendix 3. Student opinion survey}

Here are a number of statements that may or may not describe your thoughts about the Studio learning environment and Learning Assistants. You are asked to rate each statement by bubbling a letter between $\mathrm{A}$ and $\mathrm{E}$ where the letters mean the following:

A. Strongly disagree B. Disagree C. Neutral D. Agree E. Strongly agree

Choose one of the above five choices that best expresses your feeling about the statement. If you don't understand a statement, leave it blank. If you understand, but have no strong opinion, choose $\mathrm{C}$.

Compared to a traditional lecture/lab course, in the studio classroom...

1. I interact more with my instructor.

2. I ask more questions.
3. I interact more with my peers.

4. I feel nervous or uncomfortable.

5. I am more motivated.

6. I have more trouble staying focused.

7. Concepts are better connected.

8. I am more likely to attend class.

9. I solve more problems.

10. More time is spent on direct instruction (lecture).

11. The course is better suited overall for learning chemistry.

12. The course is more academically rigorous.

13. I enjoy the course more.

Compared to a course without Learning Assistants, in this class with Learning Assistants...

1. I ask more questions.

2. I interact more with my peers.

3. I feel nervous or uncomfortable.

4. I am more motivated. 
5. I have more trouble staying focused.

6. Concepts are better connected.

7. I am more likely to attend class.

8. I solve more problems.

9. The course is better suited overall for learning chemistry.

10. The course is more academically rigorous.

11. Using Learning Assistants can be an effective way to increase the involvement of women and other underrepresented groups in chemistry.

12. I enjoy the course more.

13. I would like to apply to be a Learning Assistant in the future.

\section{Acknowledgements}

The authors acknowledge the California Polytechnic State University College of Science and Mathematics College Based Fee program and the California State University 2014 Promising Practices grant program, for financial support of this research. None of this work could be accomplished without the generous and faithful support of our studio chemistry faculty, particularly Drs Seth Bush, Derek Gragson, and Grace Neff for their significant contributions to the studio program. Our studio classrooms would not exist without the dedication of Drs Phil Bailey and Christina Bailey who championed the studio concept from the beginning.

\section{References}

Adams W., Perkins K., Dubson M., Finkelstein N. and Wieman C., (2004), The Design and Validation of the Colorado Learning Attitudes about Science Survey, in Physics Education Research Conference 2004, Sacramento, California (PER Conference), pp. 45-48.

Adams W., Perkins K., Podolefsky N., Dubson M., Finkelstein N. and Wieman C., (2006), New instrument for measuring student beliefs about physics and learning physics: The Colorado Learning Attitudes about Science Survey, Phys. Rev. Spec. Top.-Ph., 2(1), 10101, DOI: 10.1103/PhysRevST PER.2.010101.

Adams W. K., Wieman C. E., Perkins K. K. and Barbera J., (2008a), Modifying and Validating the Colorado Learning Attitudes about Science Survey for Use in Chemistry, J. Chem. Educ., 85(10), 1435, DOI: 10.1021/ed085p1435.

Adams W. K., Wieman C. E., Perkins K. K. and Barbera J., (2008b), Modifying and Validating the Colorado Learning Attitudes about Science Survey for Use in Chemistry, J. Chem. Educ., 85(10), 1435, DOI: 10.1021/ed085p1435.

Bailey C., Kingsbury K., Kulinowski K., Paradis J. and Schoonover R., (2000), An Integrated Lecture-Laboratory Environment for General Chemistry, J. Chem. Educ., 77(2), 195, DOI: 10.1021/ ed077p195.

Beichner R. J., Saul J. M., Abbott D. S., Morse J. J., Deardorff D., Allain R. J., Bonham S. W., Dancy M. and Risley J., (2007), The Student-Centered Activities for Large Enrollment Undergraduate Programs (SCALE-UP) Project Abstract, Physics, 1(1),
1-42, available at: http://www.percentral.com/PER/per_reviews/ media/volume1/SCALE-UP-2007.pdf.

Bieron J. F., McCarthy P. J. and Kermis T. W., (1996), A New Approach to the General Chemistry Laboratory, J. Chem. Educ., 73(11), 1021, DOI: 10.1021/ed073p1021.

Bopegedera A. M. R. P., (2011), Putting the Laboratory at the Center of Teaching Chemistry, J. Chem. Educ., 88(4), 443-448, DOI: 10.1021/ed100045z.

Bransford J. D., Brown A. L. and Cocking R. R., (2004), How people learn: brain, mind, experience, and school, Washington DC: National Academy Press.

Bretz S. L., Fay M., Bruck L. B. and Towns M. H., (2013), What faculty interviews reveal about meaningful learning in the undergraduate chemistry laboratory, J. Chem. Educ., 90(3), 281-288, DOI: 10.1021/ed300384r.

Bruck L. B., Towns M. and Bretz S. L., (2010), Faculty perspectives of undergraduate chemistry laboratory: goals and obstacles to success, J. Chem. Educ., 87(12), 1416-1424, DOI: $10.1021 /$ ed900002d.

Carnduff J. and Reid N., (2003), Enhancing undergraduate chemistry laboratories, pre-laboratory and post-laboratory exercises, examples and advice, London: Royal Society of Chemistry.

Chittleborough G., (2014), The Development of Theoretical Frameworks for Understanding the Learning of Chemistry, in Devetak I. and Glazar S. A. (ed.), Learning with Understanding in the Chemistry Classroom, Springer Science, pp. 25-40.

Cole R., (2015), Using Chemistry Education Research to Inform Teaching Strategies and Design of Instructional Materials, in Garcia-Martinez J. and Serrano-Torregrosa E. (ed.), Chemistry education: best practices, opportunities and trends, Wiley-VCH Verlag GmbH \& Co., pp. 149-180.

Coleman E. B., (1998), Using Explanatory Knowledge During Collaborative Problem Solving in Science, J. Learn. Sci., 7(3\&4), 387-427.

Cooper M. M., (1994), Cooperative Chemistry Laboratories, J. Chem. Educ., 71(4), 307, DOI: 10.1021/ed071p307.

Cooper M. M. and Kerns T. S., (2006), Changing the Laboratory: Effects of a Laboratory Course on Students' Attitudes and Perceptions, J. Chem. Educ., 83(9), 1356, DOI: 10.1021/ ed083p1356.

Cooper M. M., Cox C. T., Nammouz M., Case E. and Stevens R., (2008), An Assessment of the Effect of Collaborative Groups on Students' Problem-Solving Strategies and Abilities, J. Chem. Educ., 85(6), 866-872, DOI: 10.1021/ed085p866.

Coppola B. and Lawton R., (1995), Who has the same substance that I have?: a blueprint for collaborative learning activities, J. Chem. Educ., 72(12), 1120-1122.

Coppola B. P., Daniels D. S. and Pontrello J. K., (2001), Using Structured Study Groups to Create Chemistry Honors Sections, in Miller J., Groccia J. E. and DiBiasio D., (ed.), Student Assisted Teaching and Learning, New York: Anker, pp. 116-122.

Cotner S., Loper J., Walker J. D. and Brooks D. C., (2013), “It's Not You, It's the Room" - Are the High-Tech, Active Learning Classrooms Worth It? J. Coll. Sci. Teach., 42(6), 82-88.

Crouch C. H. and Mazur E., (2001), Peer instruction: ten years of experience and results, Am. J. Phys., 970, DOI: 10.1119/1.1374249. 
Csizmar C. M., Force D. A. and Warner D. L., (2011), Implementation of Gas Chromatography and Microscale Distillation into the General Chemistry Laboratory Curriculum as Vehicles for Examining Intermolecular Forces, J. Chem. Educ., 88(7), 966-969, DOI: 10.1021/ed1009333.

Cummings K., (1999), Evaluating innovation in studio physics, Am. J. Phys., S38, DOI: 10.1119/1.19078.

Cummings K., (2008), The Rensselaer Studio Model for Learning and Teaching: What Have We Learned? available at: http:// sites.nationalacademies.org/cs/groups/dbassesite/documents/ webpage/dbasse_072627.pdf, accessed: 1 January 2015.

Denton D. W., (2012), Enhancing Instruction through Constructivism, Cooperative Learning, and Cloud Computing, TechTrends, 56(4), 34-41, DOI: 10.1007/s11528-012-0585-1.

Dori Y. J. and Belcher J., (2005), How Does Technology-Enabled Active Learning Affect Undergraduate Students' Understanding of Electromagnetism Concepts? J. Learn. Sci., 14(2), 243-279, DOI: $10.1207 / \mathrm{s} 15327809 j \mathrm{ls} 1402 \_3$.

Freeman S., Eddy S. L., McDonough M., Smith M. K., Okoroafor N., Jordt H. and Wenderoth M. P., (2014), Active learning increases student performance in science, engineering, and mathematics, Proc. Natl. Acad. Sci. USA, 111(23), 8410-8415, DOI: $10.1073 /$ pnas.1319030111.

Gabel D. L., (1993), Use of the Particle Nature of Matter in Developing Conceptual Understanding, J. Chem. Educ., 70(3), 193-194.

Gabel D., (1998), The complexity of chemistry and implications for teaching, in Fraser B. and Tobin K., (ed.), International handbook of science education, Boston, MA: Kluwer Academic Publishers, pp. 233-248.

Gabel D. L., Samuel K. V. and Hunn D., (1987), Understanding the Particulate Nature of Matter, J. Chem. Educ., 64(8), 695-697.

Gaffney J. D. H., Richards E., Kustusch M. B., Ding L. and Beichner R. J., (2008), Scaling up education reform, J. Coll. Sci. Teach., 37(5), 48.

Glaser B., (1992), Basics of grounded theory analysis, Mill Valley, CA: Sociology Press.

Glaser B. G. and Holton J., (2007), Remodeling Grounded Theory, Hist. Soc. Res., 19(suppl), 47-68, DOI: 10.1016/j.clae.2007.06.001.

Goertzen R. M., Brewe E., Kramer L. H., Wells L. and Jones D., (2011), Moving toward change: institutionalizing reform through implementation of the Learning Assistant model and Open Source Tutorials, Phys. Rev. Spec. Top.-Ph., 7(2), 20105, DOI: 10.1103/PhysRevSTPER.7.020105.

Gottfried A. C., Sweeder R. D., Bartolin J. M., Hessler J. A., Reynolds B. P., Stewart I. C., Coppola B. P. and Holl M. M. B., (2007), Design and Implementation of a Studio-Based General Chemistry Course, J. Chem. Educ., 84(2), 265, DOI: 10.1021/ed084p265.

Hmelo-Silver C. E., (2004), Problem-based learning: What and how do students learn? Educ. Psychol. Rev., 235-266, DOI: 10.1023/ B:EDPR.0000034022.16470.f3.

Hofstein A. and Lunetta V. N., (1982), The Role of the Laboratory in Science Teaching: Neglected Aspects of Research, Rev. Educ. Res., 52(2), 201-217, DOI: 10.3102/00346543052002201.

Hofstein A. and Lunetta V. N., (2004), The laboratory in science education: foundations for the twenty-first century, Sci. Educ., 88(1), 28-54, DOI: 10.1002/sce.10106.
Hopkins T. A. and Samide M., (2013), Using a Thematic LaboratoryCentered Curriculum To Teach General Chemistry, J. Chem. Educ., 90(9), 1162-1166, DOI: 10.1021/ed300438t.

Johnson D. W. and Johnson R. T., (1999), Making cooperative learning work, Theor. Pract., 67-73, DOI: 10.1080/ 00405849909543834.

Johnson D. W., Johnson R. T. and Smith K. A., (1998), Cooperative Learning Returns To College What Evidence Is There That It Works? Change, 26-35, DOI: 10.1080/ 00091389809602629.

Johnson D. W., Johnson R. T. and Smith K., (2007), The state of cooperative learning in postsecondary and professional settings, Educ. Psychol. Rev., 15-29, DOI: 10.1007/s10648-006-9038-8.

Johnstone A. H., (1982), Macro- and micro-chemistry, Sch. Sci. Rev., 64(277), 377-379.

Johnstone A. H., (1993), The development of chemistry teaching: a changing response to changing demand, J. Chem. Educ., 70(9), 701, DOI: 10.1021/ed070p701.

Keig P. F. and Rubba P. A., (1993), Translation of Representations of the Structure of Matter and its Relationship to Reasoning, Gender, Spatial Reasoning, and Specific Prior Knowledge, J. Res. Sci. Teach., 30(8), 883-903.

Kendall D. K. and Schussler E. E., (2012), Does instructor type matter? Undergraduate student perception of graduate teaching assistants and professors, CBE Life Sci. Educ., 11(2), 187-199, DOI: 10.1187/cbe.11-10-0091.

Kiste A. L., Hooper Rebecca A., Scott G. E. and Bush S. D., (2016), Atomic Tiles: Manipulative Resources for Exploring Bonding and Molecular Structure, J. Chem. Educ., 93(11), 1900-1903, DOI: 10.1021/acs.jchemed.6b00361.

Knight J. K. and Wood W. B., (2005), Teaching More by Lecturing Less, Cell Biol. Educ., 4(4), 298-310, DOI: 10.1187/05-06-0082.

Kober N., (2015), Reaching students: what research says about effective instruction in undergraduate science and engineering, Washington D.C.: National Academies Press, available at: http://ovidsp.ovid.com/ovidweb.cgi?T=JS\&PAGE=reference\& $\mathrm{D}=\mathrm{psyc} 11 \& \mathrm{NEWS}=\mathrm{N} \& \mathrm{AN}=2015-02991-000$.

Kozma R. B. and Russell J., (1997), Multimedia and Understanding: Expert and Novice Responses to Different Representations of Chemical Phenomena, J. Res. Sci. Teach., 34(9), 949-968.

Lamba R. S., (2015), Inquiry-Based Student-Centered Instruction, in Garcia-Martinez J. and Serrano-Torrgrosa E. (ed.), Chemistry Education: Best practices, opportunities and trends, Wiley-VCH Verlag GmbH \& Co., pp. 301-318.

Larsen R. G., Monette S. and Messerle L., (2013), Strategies for chemistry instructional laboratory and curriculum design, ACS Symposium Series, DOI: 10.1021/bk-2013-1146.ch001.

Learning Assistant Program, (2012), Learning Assistant Model for Teacher Preparation in Science and Technology, (LA-TEST): Project Annual Report to the National Science Foundation, available at: http://laprogram.colorado.edu/sites/default/files/ la-program-11-12.pdf, accessed: 8 November 2015.

Legg J. C., Greenbowe T. J. and Legg M. J., (2001), Analysis of Success in General Chemistry Based on Diagnostic Testing Using Logistic Regression, J. Chem. Educ., 78(8), 1117, DOI: $10.1021 /$ ed078p1117. 
Mashl R. J., Acs B., Wiziecki E. N., Schmidt J. R. and Polik W. F., (2013), Enhancing chemistry teaching and learning through computational tools: a computational chemistry cloud prototype using WebMO, in IMSCI 2013 - 7th International Multi-Conference on Society, Cybernetics and Informatics, Proceedings, pp. 6-9.

Matz R. L., Rothman E. D., Krajcik J. S. and Banaszak Holl M. M., (2012), Concurrent enrollment in lecture and laboratory enhances student performance and retention, J. Res. Sci. Teach., 49(5), 659-682, DOI: 10.1002/tea.21016.

Montgomery D. C., (2013), Nested and Split-Plot Designs, in Design and Analysis of Experiments, 8th edn, Hoboken, NJ: John Wiley \& Sons, Inc., pp. 604-620.

National Research Council, (1996), National Science Education Standards, Washington, DC: National Academy Press.

National Research Council, (2015) Reaching Students, Washington, D.C.: National Academies Press, DOI: 10.17226/18687.

Nogaj L. A., (2013), Using active learning in a studio classroom to teach molecular biology, J. Coll. Sci. Teach., 42(6), 50.

Otero V., Finkelstein N., McCray R. and Pollock S., (2006), Professional development. Who is responsible for preparing science teachers? Science, 313(5786), 445-446, DOI: 10.1126/ science.1129648.

Otero V., Pollock S. and Finkelstein N., (2010), A physics department's role in preparing physics teachers: the Colorado learning assistant model, Am. J. Phys., 78(11), 1218, DOI: 10.1119/1.3471291.

Ozmen H., (2004), Some student misconceptions in chemistry: a literature review of chemical bonding, J. Sci. Educ. Technol., 13(2), 147-159.

Perkins K. K., Barbera J., Adams W. K. and Wieman C. E., (2007), Chemistry vs. Physics: A Comparison of How Biology Majors View Each Discipline, in AIP Conference Proceedings, AIP, pp. 53-56, DOI: 10.1063/1.2508689.

Physics Education Technology and Physics Education Research Group at Colorado, (1998) Colorado Learning Attitudes about Science Survey, available at: http://www.colorado.edu/sei/ surveys/Faculty/CLASS-CHEM-faculty.html, accessed: 25 February 2016.

Posner G. J., Strike K. A., Hewson P. W. and Gertzog W. A., (1982), Accommodation of a Science Conception: Toward a Theory of Conceptual Change, Sci. Educ., 66, 211-227.

Prat-Resina X., Holmes J. and Moore J. W., ChemEd DL: Models 360, available at: http://www.chemeddl.org/resources/models360/ models.php, accessed: 5 December 2016.

Reid N. and Shah I., (2007), The role of laboratory work in university chemistry, Chem. Educ. Res. Pract., 8(2), 172-185, DOI: 10.1039/B5RP90026C.

Russell A. A., (1994), A Rationally Designed General Chemistry Diagnostic Test, J. Chem. Educ., 71(4), 314, DOI: 10.1021/ ed071p314.

Sandi-Urena S., Cooper M. M., Gatlin T. A. and Bhattacharyya G., (2011), Students' experience in a general chemistry cooperative problem based laboratory, Chem. Educ. Res. Pract., 12(4), 434, DOI: $10.1039 /$ c1rp90047a.
Sandi-Urena S., Cooper M. and Stevens R., (2012), Effect of cooperative problem-based lab instruction on metacognition and problem-solving skills, J. Chem. Educ., 89(6), 700-706, DOI: 10.1021/ed1011844.

Schwartz D. L., Lin X., Bransford J. D. and Brophy S., (1999), Toward the Development of Flexibly Adaptive Instructional Design, in Reigeluth C. M. (ed.), Instructional-Design Theories and Models, Mahwah, NJ: Lawrence Erlbaum Associates, pp. 183-213.

Silverthorn D. U., (2006), Teaching and learning in the interactive classroom, Adv. Phys. Educ., 30(4), 135-140, DOI: 10.1152/advan.00087.2006.

Stieff M. and Wilensky U., (2003), Connected Chemistry Incorporating Interactive Simulations into the Chemistry Classroom, J. Sci. Educ. Technol., 12(3), 285-302.

Taber K. S., (2015), The Role of Conceptual Integration in Understanding and Learning Chemistry, in GarciaMartinez J. and Serrano-Torregrosa E. (ed.), Chemistry education: best practices, opportunities and trends, Weinheim, Germany: Wiley-VCH Verlag GmbH \& Co., pp. 375-381.

Taylor S. S., (2008), Effects of Studio Space on Teaching and Learning: Preliminary Findings from Two Case Studies, Inn. High. Educ., 33(4), 217-228, DOI: 10.1007/s10755-008-9079-7.

The Concord Consortium, (2008), The molecular workbench database of curriculum, models and activities, available at: http://mw.concord.org/modeler/, accessed: 22 July 2015.

Topping K. and Ehly S., (1998), Introduction to Peer-Assisted Learning, in Peer-Assisted Learning, pp. 1-23.

Towns M. and Kraft A., (2011), Review and synthesis of research in chemical education from 2000-2010. Paper Presented at the Second Committee Meeting on the Status, Contributions, and Future Directions of Discipline-Based Education Research.

U.C. Boulder LA Program, (2012), Learning Assistant Model for Teacher Preparation in Science and Technology, (LA-TEST) Project Annual Report to the NSF, Continuum, (Minneapolis, Minn.), DOI: 10.1212/01.CON.0000415441.11964.61.

Varma-Nelson P. and Coppola B. P., (2005), Team Learning, in Pienta N. and Cooper M. M. (ed.), Chemist's Guide to Effective Teaching, Saddle River, NJ: Pearson, pp. 155-169.

Vygotsky L. S., (1978), Cole M., John-Steiner V., Scribner S. and Souberman E. (ed.), Mind in society: the development of higher psychological processes, Cambridge, MA: Harvard University Press, DOI: 10.1007/978-3-540-92784-6.

Wiggins G. and McTighe J., (2005), Backwards Design, in Understanding by Design, pp. 13-34.

Wilson J. M. and Jennings W. C., (2000), Studio courses: how information technology is changing the way we teach, on campus and off, Proc. IEEE, 88(1), 72-80, DOI: 10.1109/5.811603.

Wu H.-K., Krajcik J. S. and Soloway E., (2001), Promoting Understanding of Chemical Representations: Students' Use of a Visualization Tool in the Classroom, J. Res. Sci. Teach., 38(7), 821-842.

Zimrot R. and Ashkenazi G., (2007), Interactive lecture demonstrations: a tool for exploring and enhancing conceptual change, Chem. Educ. Res. Pract., 8(2), 197-211. 